\title{
HISTORY OF ANEURYSMS
}

\author{
by \\ W. E. STEHBENS \\ Department of Pathology, University of Sydney, Sydney
}

IN the fourteenth century B.c. the Egyptians, according to Sigerist (I95I), treated aneurysms by magico-religious therapies, but the nature and site of occurrence of these lesions are not mentioned nor the term applied to them. Ruffer (I9II) claimed that arterial degenerative diseases were prevalent amongst the Egyptians, so aneurysms of the aorta almost certainly occurred, though no reference to them has been found. Major (1954, p. 5 I), quoting Ebbell, lists aneurysm and arteriovenous aneurysm amongst the diseases described in the Ebers Papyrus. The religious fears of the Egyptian embalmers seems to have been greater than their curiosity in the vast quantity of pathological material they handled, as Long (1933) suggests, for the diseases mentioned were primarily those discernible on external examination of the body.

From this time till the second century A.D. there appears to be no existing medical literature on aneurysms. It is probable that knowledge of these lesions was mainly handed on by word of mouth. Paulus Aegineta, translated by Adams (1846), quotes Galen as having said

an artery having become anastomosed (i.e. dilated) the affection is called an aneurism; it arises also from a wound of the same, when the skin that lies over it is cicatrized, but the wound in the artery remains, and neither unites nor is blocked up by flesh. Such affections are recognized by the pulsation of the arteries, but if compressed the tumour disappears in so far, the substance which forms it returning back into the arteries.

Galen is thus to be considered the first to define and describe the disease, recognizing the false variety and those arising spontaneously by dilatation. Adams states that Galen knew of and treated traumatic aneurysms, following venesection, in the cubital fossa. Considering the frequent use of venesection, and the fact that he is said by Castiglioni (194I, p. 2 I 8 ) to have been physician to the gladiators, Galen probably saw traumatic aneurysms rather frequently. These lesions were easier to observe than the more deep-seated non-traumatic aneurysms which in modern medicine are more common.

Antyllos, who according to Major (1954, p. 204) appeared like a 'comet on the surgical horizon', made his greatest achievement by treating aneurysms in the second century A.D. Antyllos also recognized both the false and true varieties. Aetius in the sixth century, in a selected passage translated by Erichsen in 1884 (p. 4), described the clinical signs of aneurysms mentioning that they can occur in any part of the body, even in the head. It is uncertain, however, that Aetius was referring to intracranial lesions; he claimed that bronchocoele in parturient women was the commonest form of aneurysm, but it would seem he was alluding to goitres. 


\section{History of Aneurysms}

There is another lapse in progress until the sixteenth century when Fernel in $154^{2}$ (quoted by Erichsen, pp. 4-5) claimed aneurysms occurred 'in the chest, or about the spleen and mesentery where a violent throbbing is frequently observable'. Garrison (1943, p. I 73) said that Saporta in I554 gave the earliest description of an aortic aneurysm and that Vesalius a year later (p. 173) was the first to diagnose such.

The ancients mainly considered that an aneurysm was formed by rupturing of the arterial coats, because they were familiar with the aetiology of the traumatic false variety. This idea of rupturing of the inner coat continued for a considerable time, and probably their knowledge of the traumatic origin in the case of the false sac influenced them in their belief that those without trauma must have arisen by a sudden breach in the arterial wall. Castiglioni (p. 247) says Antyllos believed that some appeared by simple dilatation, and Fernel in 1542, translated by Erichsen (pp. 4-5), was of the same opinion. According to Erichsen (pp. 9-10), Sennertus in 1628 scorned this opinion, declaring they were due to rupture of the inner coat and were in fact a dilatation of the external coat.

In the middle of the sixteenth century, syphilis was considered as a cause of aneurysmal dilation, but whether it was Fernel, as Long, quoted by Mettler (1947), suggests, or the famous barber-surgeon Ambroise Paré, as Zimmermann (1935) and Garrison (p. 306) think, is uncertain. Paré, it seems, also said that they could be caused by 'anastomosis, diapedesis, rupture, erosion and wound' and realized that not all aneurysms are pulsatile, attributing the absence of pulsation to the large amount of thrombus in the sac.

In Erichsen's translation of the works of Guillemeau (I595), the latter author wrote that the

tumour called aneurism is usually considered to be a dilatation of the artery, which can only apply to small aneurisms, as it is impossible that the artery can really be dilated and enlarged to the size of the large aneurisms that are often met with. Following therefore the opinion of the ancients we will say that an aneurism is occasioned when the blood and spirits pass out of the vessels.

Wiseman ( 1676 , translated by Erichsen, pp. I I-I4) denied that aneurysms were caused by rupture of the inner coats, with dilatation of the outer, but believed they were due to rupture of all coats with extravasation of blood into the surrounding tissues. The internal causes of aneurysms were supposed to be the 'impetuosity of the blood'.

The impetus [he said] may arise, first from the quantity of the blood, either when it is more than the vessel can contain [or else when the blood is] too forcibly driven forwards from the heart towards some peculiar artery, when the farther progress being (it may be) intercepted by some violent contraction of the muscles through which it must pass, it of necessity breaks the vessel.

Another endogenous factor he considered was an erosive quality of the blood, while external factors were entirely traumatic. 


\section{W. E. Stehbens}

Bourdelot (168I), in his discussion of aneurysms, translated by Erichsen (pp. 207-13), mentions that he knew of a woman with five or six aneurysms of chronic nature, though their aetiology was obscure. He reflects on cases of spontaneous non-traumatic aneurysms, suggesting that they were caused by a 'giving away' of the middle tunic of the arteries, the result of 'the ebullition of the blood' with consequent dilatation. He stated that the 'commonest and best known kind of aneurism is that which happens in consequence of the artery being punctured by venesection', a complaint from which he said he suffered himself. Furthermore, he denied that arteries never communicated with veins, so perhaps he may have been thinking of an arteriovenous anastomosis of the cubital fossa.

Lancisi (1728) in his book De Aneurysmatibus, published posthumously, discusses the etymology of the term aneurysm, mentioning the opinions of various authors as to its derivation. He emphasized the past classification of 'genuine and spurious' aneurysms, as well as those of the heart. He was of the opinion that an artery must be weakened very much before it dilates, and suggests that the impetus of the circulating blood is a factor in dilatation. Lancisi is possibly the first to infer that a congenital defect may be the cause of aneurysmal dilatation in some cases, for he says an artery may be 'constructed by nature with fibers too slack and too small'. This conjecture of 'inherent weakness' of the vessel wall is hard to disprove and was based solely on supposition and autopsies of adult patients with aneurysms, where the arteries appeared thinner than usual.

Alexander Monro ( 1733 ), according to Erichsen (pp. 81-8), described three coats of the arterial wall, and the destruction of the wall in the formation of true and false aneurysms. He considered true aneurysms to be rare, being caused by a palsy, with resultant yielding of the muscle layer to the distending force of the blood. In a true aneurysm he required the media to be intact which state was rarely to be found. His method of study does not seem to include any microscopic evidence, and obviously he did not realize that the elastic and muscle components undergo fibrous tissue replacement at an early stage.

In 1736 Petit is said by Erichsen (pp. 89-98) to have stated that true aneurysms could give rise to and resemble a false sac, and vice versa. Also he appears to be the first to realize that an aneurysm could undergo repeated minor ruptures.

Castiglioni (p. 626) and Garrison (p. I 73) both credit William Hunter with the first description of an arteriovenous aneurysm in 1757 , and this description was indeed clear. However, Bourdelot in 168I (translated by Erichsen, pp. 207 213) in his writings on traumatic lesions of vessels claimed to have seen arteriovenous anastomoses, though no description is given. William Hunter like Petit, knew of a mixed true and false variety of aneurysm.

Home, I 793 (according to Erichsen, pp. 388-9), recorded that John Hunter, the younger and more renowned brother of William, exposed the carotid artery of a dog, dissected off much of the wall, till it was extremely thin, and blood could be seen through it. Then three weeks later he re-exposed the part 
and found no dilatation, but only a repaired vessel wall. He concluded that pre-existing arterial disease was required to produce an aneurysm, because the damage he had done was greater than one would expect as the result of accidental trauma.

Home objected to this, feeling that the surrounding tissues closed upon the weakened segment of artery to reinforce it, so he himself repeated the experiment on the femoral artery of a dog, and covered the part with lint to prevent the neighbouring tissues from reinforcing it. After six weeks no dilatation or constriction was found. Home therefore agreed with John Hunter that a pre-existing arterial disease was of the utmost importance in the aetiology of aneurysms. Though these experiments do not prove the theory of the observers, they are important for their experimental approach to pathology. Home realized that the wall of a true aneurysm need not have the structure of a normal arterial wall.

Shennan (1934) cited Morgagni ( 1760 ) as having recorded several cases of aortic aneurysm in which blood had forced its way obliquely and by degrees through the wall, and 'coming out under the external coat of the artery, first by drawing it from the internal coats and then by raising it as a large kind of ecchymosis'. These cases were probably dissecting aneurysms. Shennan, however, considered that it was Maunoir (1812) who first clearly suggests a dissection of the arterial coats, and Laennec (1826) as the first to use the term anévrysme disséquant.

Donald Monro in 1760 (Erichsen, pp. 137-8) believed that aneurysms were formed by dilatation of all coats, and not due to rupture of the inner, with dilatation of the external. On macroscopic dissection he found the inner coats of the parent artery to pass into the wall of the sac; he placed much reliance on this observation. He recalled a patient who died of multiple aneurysms which were dissected by Monro's brother. All the coats of the vessel wall were found to be present in the smaller sacs, but were imperfect in the larger. Donald Monro concluded from this that the larger sacs were formed in the same manner as the smaller, but that by continued stretching and by the admixture of other substances with the coats, the demonstration of the layers of the dilated wall was impracticable. Furthermore, he thought that by dilatation of the vessel, the perivascular connective tissues could be incorporated in the wall of the sac.

Laminated thrombus in aneurysms was described by Baillie in 1770 (Erichsen, pp. 1 75-9), though not for the first time, and he believed that it was extremely rare but possible for the thrombus to so fill the sac as to effect a cure and obviate the need for surgical treatment. According to Long, Baillie adequately described aneurysm of the aortic arch and aortitis, but overlooked atherosclerotic changes in the vessel. Atherosclerotic changes in association with aneurysm had been previously mentioned by Donald Monro in 1760 (Erichsen, p. 138 ), who considered them as secondary, and by Paré in 1582 (Erichsen, p. 7). Paré stated that after rupture of the wall, the coats took 'from the neighbouring parts matters similar to themselves in order to re-unite' and 'little by 


\section{W. E. Stehbens}

little the circumference of the tumour dries and hardens, like a vessel becoming cartilaginous and then osseous'.

Bromfield in 1773 (Erichsen, pp. 347-8) regarded the pre-existing disease as being of importance in the aetiology, for aneurysms were often multiple.

In the nineteenth century much progress was made, not only in the pathological field but also on the clinical, surgical and radiological sides. Long (1933) says that Scarpa (I801) contended that an aneurysm resulted from rupture of the intima and media, and that atheromatous ulceration was the prime cause of such rupture. Also he was inclined to believe that aortic aneurysms were related to syphilis, but this was not the sole cause, for he demonstrated that atheroma was very prevalent in syphilitics.

Castiglioni (I94I) writes that Hodgson so impressed the French with his treatise on vascular diseases published in 1815 that they referred to aortic aneurysm as the maladie d'Hodgson. Long says Hodgson believed aneurysms developed by the blood passing through the atheromatous ulcers, and then distending the adventitia.

Hasse (1846) gave a most exhaustive but confusing classification of aneurysms even including telangiectases, but was a firm believer in atheroma predisposing to aneurysm formation. He did not infer that rupture of the intima and media were necessary for aneurysmal dilatation, but rather it was a gradual atheromatous degeneration of these coats, with the loss of elasticity and then dilatation of the whole wall.

Rokitansky (1852) discussed at great length the pathogenesis of aneurysms. He stated that the media was thinned and could not be traced far into the sac, sometimes terminating abruptly at its entrance, and denied that a laceration of the inner coats had ever been demonstrated or that a fissure could produce a saccular aneurysm. Rokitansky said that for a considerable time aneurysms had been considered the result of a 'special aneurismal diathesis' due to their apparent spontaneous non-traumatic origin and to the incidence of multiplicity.

It was about the middle of the nineteenth century that the knowledge of arterial disease commenced to progress more rapidly, and Long attributes this to the advent of the microtome and microscope as well as the pathologists, especially Virchow. However, at this time the rôle of syphilis was still confused, though it was thought to be an additional factor in the aetiology of aneurysms. Garrison (p. I42) considered the work of Wilks in 1863 on visceral syphilis an important step in the final acceptance of this disease as a causative agent. Long reports that Welch (1875) finally separated syphilitic aortitis from atheroma. Furthermore, he considered that it was chiefly the syphilitic changes which progressed to aneurysm formation in the aorta.

Coats and Auld (1893) studied early aneurysmal sacs in the aorta, concluding that atheroma was of great importance. They stained elastic fibres, and found that in early sacs at the entrance, the elastica ended fairly abruptly or tapered off eventually to disappear.

In the twentieth century, atheroma and syphilis have been accepted quite definitely as being the two most important aetiological agents in the production 


\section{History of Aneurysms}

of non-infective aortic aneurysms, and the rôle each plays has been elucidated by the assistance of the discoveries of the Treponema pallida and the introduction of serological tests for syphilis. False aneurysms are now recognized as being much less frequent.

There are, however, still some doubts about the aetiology of some aneurysms such as those on splanchnic vessels, and those of the aorta associated with coarctation of the aorta and arachnodactyly. Both varieties often being considered congenital, or more correctly acquired as the result of a congenital weakness. It is hoped that these, too, will be explained adequately in the near future.

\section{Conclusion and Summary}

Aneurysms were recognized in very early times, and were mainly those seen on superficial inspection of the body. They were mainly traumatic in origin, presumably due to the frequent use of venesection, and to a lesser extent the warfaring habits of the people of those days. The ancients realizing the traumatic origin of the pulsatile swellings, applied this knowledge to the saccular dilatations occurring without a history of trauma. They consequently believed that all aneurysms were ultimately of the same origin, namely an abrupt interruption of all or part of the vessel wall. This theory of rupture of the coats persisted for a considerable time because they could not understand the difference in the composition of the wall of the parent artery and that of its diverticulum. Periodically the theory was denied, and eventually established as false.

The author feels that a somewhat similar state of affairs exists in the case of cerebral aneurysms today. Here too there has been difficulty in understanding the transition from normal vessel wall to the aneurysmal wall; and numerous theories have been put forward, but as yet the true aetiology has not been explained to the satisfaction of all.

\section{ACKNOWLEDGEMENTS}

My thanks are due to Professor F. R. Magarey for his friendly advice in the preparation of this article.

\section{BIBLIOGRAPHY}

Adams, F., The Seven Books of Paulus Aegineta, translated from the Greek with a commentary, London, Sydenham Society, 1846, II, 31 .

Castiglioni, A., A History of Medicine, translated from the Italian and edited by E. B. Krumbhaar, New York, Alfred A. Knopf, 194I.

Coats, J., and Auld, A. G., 'Preliminary Communication of the Pathology of Aneurysms with Special Reference to Atheroma as a Cause', Brit. M.F., 1893, II, 456-6o.

ERICHSE N, J. E., Observations on Aneurism, London, Sydenham Society, 1844.

Garrison, F. H., revised by L. T. Morton, A Medical Bibliography, London, Grafton \& Co., 1943.

HAsse, C. E., An Anatomical Description of the Diseases of the Organs of Circulation and Respiration, translated and edited by W. E. Swaine, London, Sydenham Society, 1846, pp. 83-97. 


\section{W. E. Stehbens}

Lancisi, G. M., De Aneurysmatibus Opus Posthumum, revised with translation and notes by W. C. Wright, New York, The Macmillan Co., 1952.

Lon G, E. R., Arteriosclerosis, edited by E. V. Cowdry, New York, The Macmillan Co., 1933, Chapter 1, p. 23.

MAJOR, R. H., A History of Medicine, Illinois, Charles C. Thomas, 1954, I, 5 I and 204.

Metrte R, G. C., History of Medicine, edited by F. A. Mettler, Philadelphia, The Blakiston Co., 1947, p. 250.

Roxitansky, G., A Manual of Pathological Anatomy, translated by G. E. Day, London, Sydenham Society, 1852, Iv, 275-83.

Ruffer, M. A., 'On Arterial Lesions Found in Egyptian Mummies', 7. Path. EO Bact., $1911, \mathrm{xv}, 453$.

Shen nan, T., Dissecting Aneurysms, Medical Research Council, Special Report Series No. 193, His Majesty's Stationery Office, London, 1934.

Sigerist, H. E., A History of Medicine, New York, Oxford University Press, 1951, 1, 273.

Zimmerman, E. L., 'The Pathology of Syphilis as revealed by Autopsies Performed between I563 and 176r', Bull. Hist. Med., 1935, p. 355 . 